\title{
Unmet need for presbyopia correction and its associated factors among school teachers in Hawassa city, South Ethiopia
}

\author{
Minychil Bantihun Munaw ${ }^{1 *}$, Balcha Negese Kebede ${ }^{2}$ and Nebiyat Feleke Adimassu'
}

\begin{abstract}
Background: Presbyopia is a decline in the amplitude of accommodation with the onset in the age range 40-45 years affecting near visual task performance. As the age of presbyopia onset coincides with productive age, it results in great productivity loss especially in those with high near visual demand like teachers. A maximum near vision potential is essential for teachers in ensuring the quality of education, as most of the students' evaluations and scripts are assessed manually in Ethiopia. The prevalence of unmet need for presbyopia correction among school teachers ranges from $38.5-70.4 \%$ worldwide. Though presbyopia is a common ocular condition, there is limited evidence regarding the unmet need for presbyopia correction in Ethiopia as well as in Hawassa city. Therefore, this study aimed to determine the magnitude of unmet need for presbyopia correction and its associated factors among school teachers in Hawassa city, South Ethiopia.

Methods: A school-based cross-sectional study was conducted among teachers older than 35 years. A simple random sampling technique was used to select participants using name lists as a sampling frame from 69 schools. The participants selected underwent for distance and near visual acuity test. Those with distance visual acuity of 6/ 12 or worse were refracted before near visual acuity test. Information on the spectacle use and associated factors was obtained using the interviewer-administered questionnaire. Data analysis was done using Statistical Package for Social Sciences software version 20. Binary logistic regression analysis was performed to assess association between independent variables and the unmet need for presbyopia correction.

Results: A total of 459 study participants were included in the study with a response rate of $95.21 \%$.The unmet need for presbyopia correction was 51.26\% (95\%Cl: 46.7-55.6\%). Female gender ( $\mathrm{AOR}=2.50$; 95\%Cl: 1.51-4.15), age 36-45 $(\mathrm{AOR}=4.12 ; 95 \% \mathrm{Cl}: 1.46-11.76)$, unaware of presbyopia ( $\mathrm{AOR}=2.36 ; 95 \% \mathrm{Cl}: 1.2-4.66)$ and self-rating of current vision as good (AOR $=3.5 ; 95 \% \mathrm{Cl}$ : 1.61-7.6) were factors significantly associated with the unmet need for presbyopia.

Conclusions: The burden of unmet need for presbyopia correction is a moderate priority according to the World Health Organization for presbyopia correction services criteria. A school-based presbyopia awareness creation program is important to reduce this huge burden.
\end{abstract}

Keywords: Unmet need for presbyopia correction, School teachers, Hawassa Ethiopia

\footnotetext{
* Correspondence: minychilmedban@gmail.com

${ }^{1}$ Department of Optometry, College of Medicine and Health Sciences,

University of Gondar, P.O.Box: 196, Gondar, Ethiopia

Full list of author information is available at the end of the article
}

\section{$\triangle B M C$}

(c) The Author(s). 2020 Open Access This article is licensed under a Creative Commons Attribution 4.0 International License, which permits use, sharing, adaptation, distribution and reproduction in any medium or format, as long as you give appropriate credit to the original author(s) and the source, provide a link to the Creative Commons licence, and indicate if changes were made. The images or other third party material in this article are included in the article's Creative Commons licence, unless indicated otherwise in a credit line to the material. If material is not included in the article's Creative Commons licence and your intended use is not permitted by statutory regulation or exceeds the permitted use, you will need to obtain permission directly from the copyright holder. To view a copy of this licence, visit http://creativecommons.org/licenses/by/4.0/ The Creative Commons Public Domain Dedication waiver (http://creativecommons.org/publicdomain/zero/1.0/) applies to the data made available in this article, unless otherwise stated in a credit line to the data. 


\section{Background}

Presbyopia is a global problem affecting over a billion people older than 34 years worldwide $[1,2]$. It is a progressive age-related loss in the amplitude of accommodation due to crystalline lens growth and changes in its elastic properties with the onset of less than 40 years of age in females and Africans [3-5]. The number of people with presbyopia who do not have spectacles was estimated to be 826 million in 2015 [2].

The symptoms of presbyopia are visual discomfort such as eye strain, headache, and difficulty to perform near visual tasks such as reading $[3,6]$. Lack of clear near vision prevents teachers from regular reading, faces difficulty in checking students' class work, marking exams, and doing manuscripts, especially where those activities are done manually like in Ethiopia. Therefore, the cumulative effect of uncorrected presbyopia on daily teaching activities has a great impact on the quality of education.

As a result of their long work experience, the older teachers have an invaluable role in ensuring the quality of education. However, presbyopia limits these teachers from contributing to full potential. Besides, presbyopia has a huge economic impact because its onset coincides with productive age [5]. From the literatures reviewed, the unmet need for presbyopia correction ranges from 4 to $96.8 \%$ [7-14] in the community and 38.5 to $70.4 \%$ for school teachers $[3,4,12,15]$ worldwide.

When setting the priority for presbyopia service provision, the World Health Organization sets recommendations. It sets as high priority if only less than one-third presbyopics had presbyopia correction, moderate if one- third to twothird presbyopics had presbyopia correction and low if more than two-third presbyopics had presbyopia correction [16].

Although the burden of presbyopia affects productivity, there are many people left uncorrected for several reasons. Being female, high cost of spectacles, illiteracy, and lack of awareness about where to access presbyopia correction, availability, and access to eye care services were barriers for use of presbyopia corrections [1, 15-18].

A proper estimate of the unmet need for presbyopia correction is essential for advocacy, planning, establishing refraction, and spectacle distribution for teachers at the government level. However, there is little information on the unmet need for presbyopia correction and its associated factors among school teachers in Ethiopia, particularly in Hawassa city. Hence, it is imperative to estimate the unmet need for presbyopia correction and identify factors that affect access to correction among school teachers.

\section{Methods}

\section{Study population and study design}

A school-based cross-sectional study was conducted from April 25 to May 30, 2019, to assess the unmet need for presbyopia correction among school teachers in
Hawassa city. Hawassa is the capital city of Southern Nation, Nationalities and Peoples' Regional State (SNNPR) which is located $276 \mathrm{Km}$ from Addis Ababa, the capital. The urban population of Hawassa in the 2018 projection was 266,331. From these 137,316 are males and 129,015 are females. It has eight urban subcity administration and 20 Kebeles (local administrative). A total number of 1569 teachers older than 35 years were teaching in 69 schools in urban kebeles of Hawassa city, of which 963 were teaching in public schools and 606 were teaching in private schools. There are two hospitals, one comprehensive specialized hospital, and one general hospital, three private specialized higher eye clinics, and one medium optometry clinic providing eye care services including refraction (spectacle correction).

\section{Sample size determination and sampling procedure}

The sample size was calculated for the proportion of unmet need using a single population proportion formula and associated factors using EPI INFO 7 with the assumption of $95 \%$ confidence level and power $80 \%$. The largest sample size was chosen to assure the representativeness of the sample.

The sample size for the proportion of unmet need = $\frac{z^{\alpha} / 2 P(1-P)}{d^{2}}=\frac{(1.9)^{2}(0.692)(0.308)}{(0.05)^{2}}=\approx 327$, where $\mathrm{p}-0.692$ from a community-based study in Bahir Dar city, North West Ethiopia [17], level of significance (95\%) and margin of error $(d)=0.05$.

Being female was one of the factors frequently associated with the unmet need for presbyopia correction in our literature reviews that gives a larger sample size. Using unexposed to exposed ratio 1:1, OR 1.78, outcome among unexposed (i.e. male gender 70.9\%) from a study in Bahir Dar city, North West Ethiopia [17], the sample size generated with EPI INFO 7 for this factor was 568. Since the population size is $<10,000$ using correction formula

- $n \mathrm{f}=\frac{n}{1+\frac{\mathrm{n}}{\mathrm{N}}}=\frac{568}{1+\frac{568}{1569}}=417$ by taking $10 \%$ non-response rate

- $\mathrm{nf}=417+417^{* 10} / 100$
$41.7=\approx 459$ (non-response rate) $=417+$

Therefore, the final sample size used was 459 .

A simple random sampling technique was used to select the samples proportionally from 69 schools. The number of teachers older than age 35 years in each school was identified by asking their current age using their name list. Using their name list as a sampling frame, 459 study participants were proportionally selected by the lottery method from all 69 schools. The selected participant who fulfilled the inclusion criteria (older than 35 years of age, whose near binocular VA 
worse than point 8 (N8) with best distance correction, and can improve to point 8 (N8) or better after refraction) was included in the study. The next study participant was selected using the lottery method if a selected individual didn't fulfill the inclusion criteria (Fig. 1).

\section{Data collection tool and procedures}

Data collection was done by trained 10 optometrists using a pre-tested structured questionnaire in Amharic version converted by a language expert, which ascertained information about socio-demographic data, associated factors, and a noninvasive ocular examination using a penlight, streak retinoscope, and full trial set and literate near acuity chart (Nchart). Distance visual acuity (unaided or habitual) was measured under the ambient light condition on the room corridor using Snellen's E chart. Refraction with streak retinoscopy and subjective refinement was done for those with reduced unaided or habitual distance visual acuity (VA $=6 / 12$ or worse in both measurements) and their near visual acuity was tested after best distance correction. Near visual acuity was directly measured for participants whose unaided or habitual distance visual acuity was $6 / 9$ or better. Near visual acuity was measured for all selected individuals and for those with near visual acuity worse than N8 refraction was performed by adding $+0.25 \mathrm{DS}$ step by step until there is no difference with additional + 0.25DS lens. The final powers of the lens required to read the smallest line and near visual acuity were recorded. Two additional visits were conducted to get study participants who did not avail at the first visit.

\section{Operational definition}

Presbyopia is defined as an inability to read N8 at $40 \mathrm{~cm}$ with best correction at distance, which can be corrected to N8 or better with near correction $[19,20]$.

Clinically significant presbyopia is defined as near visual acuity correction of $\geq+1.00 \mathrm{D}$ in addition to distance correction [19].

\section{Unmet need for presbyopia correction}

Number of subjects unable to see N8 binocularly unaided or with their existing near correction that can be corrected to $\mathrm{N} 8$ or better after refraction.

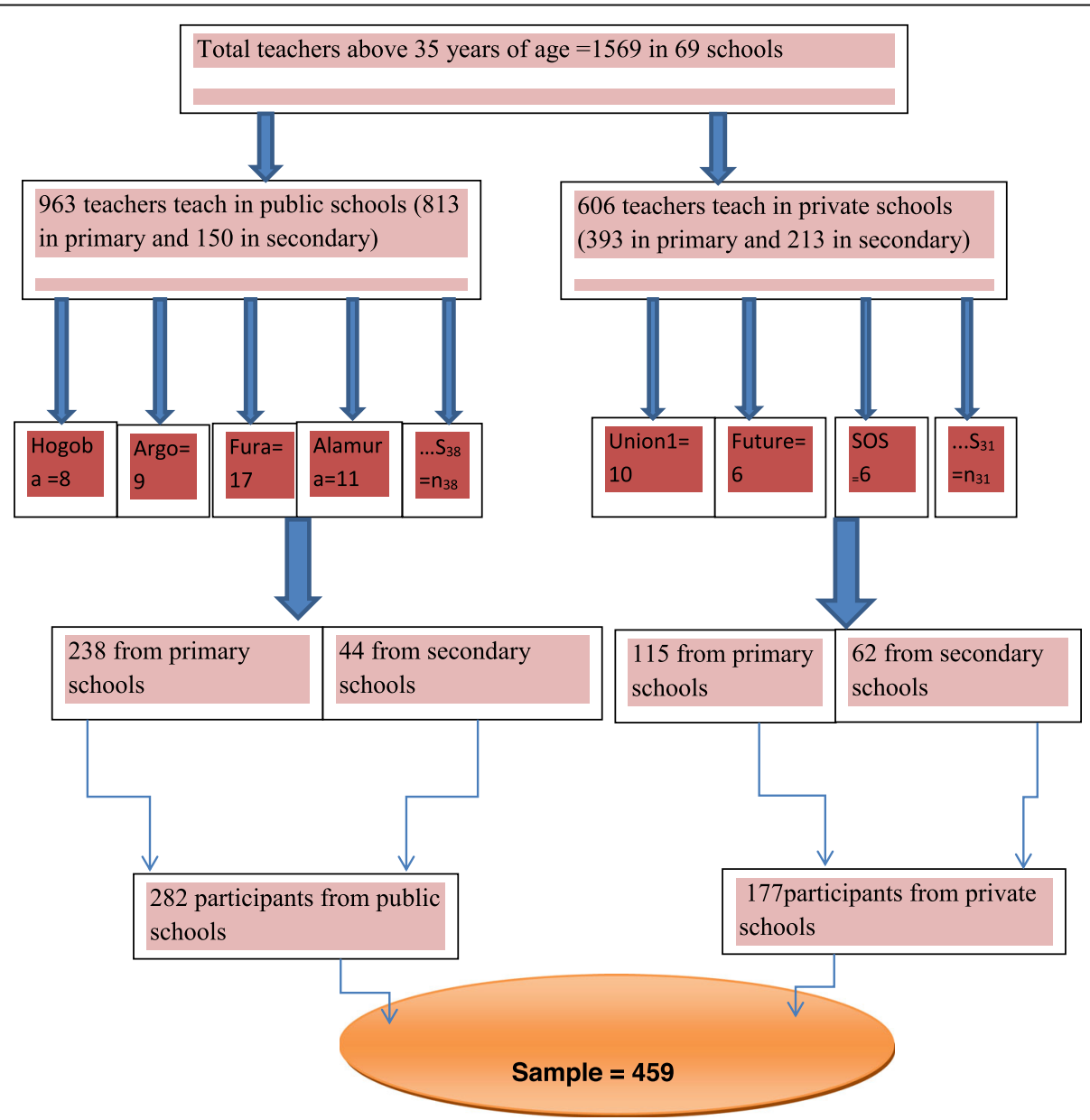

Fig. 1 Schematic representation of the sampling procedure for the unmet need for presbyopia correction among school teachers in Hawassa city, South Ethiopia 
Awareness of presbyopia is positive (aware) if answered (yes) for the question; "have you ever heard of the age-related near vision difficulty called presbyopia?"

The degree of presbyopia refers to the extent of agerelated near vision difficulty due to a decline in the amplitude of accommodation of the eye, based on presenting unaided near visual acuity at $40 \mathrm{~cm}$. Accordingly, presbyopia was classified as mild (near VA worse than N8 to N10), moderate (near VA worse than N10 to N18), and severe (near VA worse than N18) [19].

\section{Data processing and statistical analysis}

After coding, cleaning, and checking for completeness, the data was entered into EPI INFO version 7 and exported to SPSS. The descriptive part of the data analysis was summarized using frequency distribution and means. Binary logistic regression analysis was performed to identify factors associated with unmet need for presbyopia correction. Since the number of variables was small, all variables were entered into the multivariable analysis. Enter variable selection method was used to inter variables to multivariable binary logistic regression analysis. Odds ratios (OR) with 95\% confidence interval was used to assess the strength of association. A $P$-value of $<0.05$ was considered a statistically significant association. Multicolinearity was checked using variance inflation factor and goodness of fit was diagnosed with Hosmer and Lemeshow model fitness test. Hosmer and Lemeshow with a P-value of $>0.05$ was considered as good model fitness.

\section{Ethical consideration}

Before conducting the study, ethical clearance was obtained from School of Medicine, Ethical review committee, University of Gondar. An official letter was obtained from Gondar University College of Medicine and the Health Sciences Department of Optometry and Hawassa City Health Bureau. Also, oral permission was obtained from each school director after a brief explanation of the purpose of the study for school directors. Written informed consent was obtained from each study participant after explaining the aim of the study to proceed to the examination and interview step. The confidentiality of the data was ensured and the consent declared that participants' participation is voluntary. They were also informed that there is no any risk through participating in this survey. It was also clarified that they have full right to refuse from participating in the study and to withdraw at any time they wish. They would also have a full right to contact and ask the authors whatever they want.

\section{Results}

Socio-demographic characteristics of the study participants

Four hundred fifty-nine study participants were included in the study with a response rate of $95.21 \%$. The mean age of participants was 47.85 years $( \pm 7.33 S D)$. More than half of the study participants $(51.03 \%)$ were female and about two-third of study participants $(67.28 \%)$ were first degree holders (Table 1).

The proportion of unmet need for presbyopia correction The proportion of unmet need for presbyopia correction was calculated using the formula: Unmet need for presbyopia correction $=($ No of individuals without presbyopia correction/No of individuals with presbyopia correction + without presbyopia correction)* 100\%. Therefore, among 437 study participants with presbyopia, 51.26\%(46.7$55.6 \%)$ had inadequate near correction, of which females accounting for more than half (Fig. 2).

The unmet need for presbyopia correction in those with a diploma, aged 36-45 years, and earning a monthly income of (2748-5250 ETB) was 79.28, 78.8, and 71.04\% respectively (Table 1 ).

Table 1 Socio-demographic characteristics and unmet need for presbyopia correction among school teachers in Hawassa city, South Ethiopia $(n=437)$

\begin{tabular}{|c|c|c|}
\hline \multirow[t]{2}{*}{ Variables } & \multirow{2}{*}{$\begin{array}{l}\text { Frequency } \\
\mathrm{n}(\%)\end{array}$} & Uncorrected presbyopia \\
\hline & & Frequency n (\%) \\
\hline \multicolumn{3}{|l|}{ Age in years } \\
\hline $36-45$ & $212(48.51)$ & $167(78.77)$ \\
\hline $46-55$ & $132(30.21)$ & $42(31.82)$ \\
\hline$>56$ & $93(21.28)$ & $15(16.13)$ \\
\hline \multicolumn{3}{|l|}{ Sex } \\
\hline Male & $214(48.97)$ & $94(43.93)$ \\
\hline Female & $223(51.03)$ & $130(58.30)$ \\
\hline \multicolumn{3}{|c|}{ Educational status } \\
\hline Diploma & $111(25.40)$ & $88(79.28)$ \\
\hline Degree & $294(67.28)$ & $125(42.52)$ \\
\hline $\mathrm{MSc} / \mathrm{MA}$ & $32(7.32)$ & $11(34.34)$ \\
\hline \multicolumn{3}{|l|}{ Marital status } \\
\hline Married & $385(88.10)$ & $198(51.43)$ \\
\hline Single & $52(11.90)$ & $26(50.00)$ \\
\hline \multicolumn{3}{|c|}{ ancome per month in ETB } \\
\hline $2748-5250$ & $221(50.57)$ & $157(71.04)$ \\
\hline $5251-7800$ & $153(35.01)$ & $55(35.95)$ \\
\hline$>7800$ & $63(14.42)$ & $12(19.05)$ \\
\hline \multicolumn{3}{|l|}{ Type of school } \\
\hline Public & $272(62.24)$ & $122(44.85)$ \\
\hline Private & $165(37.74)$ & $102(61.82)$ \\
\hline \multicolumn{3}{|c|}{ Level of school } \\
\hline Primary & $352(80.55)$ & $191(54.26)$ \\
\hline Secondary & $85(19.45)$ & $33(38.82)$ \\
\hline
\end{tabular}

income is categorized using the 2018 Ethiopian taxation rate 


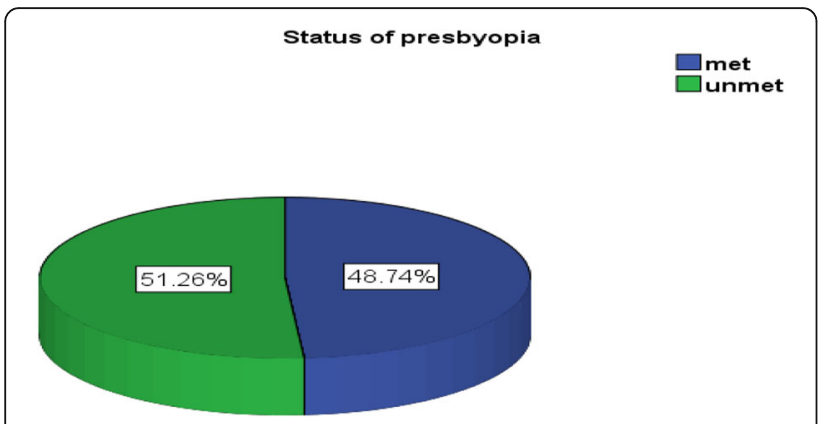

Fig. 2 Proportion of unmet need for presbyopia correction among school teachers in Hawassa city, South Ethiopia

\section{Factors associated with unmet need for presbyopia correction}

Fourteen variables as reflected in Table 2 including sex, age, educational status, marital status, monthly income, self-rating of current vision, degree of presbyopia, awareness of the presbyopia, history of the eye examination, family ocular history, type of school and school level were assessed with bivariable logistic regression analysis. Since the number of variables in this study was small, all variables were entered into a multivariable logistic regression to control for the effect of potential confounders. In multivariable analysis, being female (AOR 2.50; 95\% CI: $1.51-4.15)$, age $36-45$ years $(4.12 ; 95 \% \mathrm{CI}$ 1.46-11.76), unaware of the presbyopia (AOR 2.36; $95 \%$ CI: $1.2-4.66$ ), self-rating of current vision as good (AOR 3.5; 95\% CI: 1.61-7.65) were significantly associated with unmet need for presbyopia correction (Table 2).

Accordingly, individuals aged 36-45 years were 4.12 times more likely to have an unmet need for presbyopia correction compared with those 56 years and older. Being female was 2.50 times more likely to have an unmet need for presbyopia correction as compared to males. Individuals who were unaware of presbyopia were 2.36 times more likely to have an unmet need for presbyopia correction compared to their counterparts who were aware of it. Similarly, individuals who rate their current near vision as good despite having significant presbyopia were 3.5 times more likely to have an unmet need for presbyopia correction as compared to those who rate their current vision as poor.

\section{Discussion}

The unmet need for presbyopia correction in Hawassa city, South Ethiopia was 51.26\% (95\% CI: 46.7-55.6\%), which implies moderate priority according to the World Health Organization classification for presbyopia correction service provision. This proportion is lower than a report from Bahir Dar city, North West Ethiopia (69.2\%) [17], Eretria (84.6\%) [21], Kenya (93.7\%) [1], Zanzibar (83.4\%) [16] and Bangladesh (74.8\%) [14]. The current study was conducted on school teachers whose near visual demand is high which may force them to have correction while the previous studies were communitybased for whom detail near vision might be less essential. This difference may account for the variation of unmet need for presbyopia correction between those countries. The unmet need for presbyopia correction in this study was also, lower than studies from Nepal (90\%) [22], Prakasam district, South India (56.8\%) [11], Brazil (61\%) [13] and Nicaragua (62.9\%) [14]. The discrepancy in magnitude of unmet need of presbyopia correction might be due to the difference in study setting and residence.

The unmet need for presbyopia correction in this study was higher than reports from developing countries such as Ghana (29.6\%) [4], Info Township- Nigeria (38.5\%) [15], and Jakarta Indonesia (41.0\%) [12]. In Ghana, teachers aged 40 years and above were included using the criterion of the distance of $30 \mathrm{~cm}$ to achieve at least N8 optotype. This age difference might account for the difference in the magnitude of uncorrected presbyopia compared to our study. In Nigeria teachers above 30 years were included which may account for the variation in unmet need for presbyopia correction between the current and the study in Nigeria. The burden difference between our study and Jakarta, Indonesia might be due to the presence of a school-based eye health program that includes visual acuity screening, refraction, and provision of free eyeglasses to students and teachers in Jakarta, Indonesia [12].

The unmet need for presbyopia correction in our study was similar to reports from Ido local government of Nigeria (54.5\%) [18] and in Tanzania (46.5\%) [23]. This might be due to similarities in sample size used, the mean age of study participants, and the criteria used in both studies.

This study identified that being in the age group 3645 years, being female, unaware of presbyopia, self-rating of current near vision as good by the respondent were factors significantly associated with the unmet need for presbyopia correction.

Accordingly, being female was 2.50 times more likely to have an unmet need for presbyopia correction compared to males. This is similar to reports from Bahir Dar, North West Ethiopia [17], Info Township- Nigeria [24], and Timor-Leste [25]. Similarly, in Timor-Leste, unmet need for presbyopia correction was $79 \%$ for females while $68.8 \%$ in males. This is due to a higher prevalence and earlier onset of presbyopia in women due to physiological and physical reasons besides long life expectancy compared to men [5].

Individuals in the age group 36-45 years were almost 4 times more likely to have an unmet need for presbyopia correction compared to the age group 56 years and older. Age from 36 to 45 was similarly associated with 
Table 2 Factors associated with the unmet need for presbyopia correction among school teachers in Hawassa city, South Ethiopia $(n=437)$

\begin{tabular}{|c|c|c|c|c|}
\hline \multirow[t]{2}{*}{ Variables } & \multicolumn{2}{|l|}{ Status of presbyopia } & \multirow[b]{2}{*}{ COR, $(95 \% \mathrm{Cl})$} & \multirow[b]{2}{*}{$\mathrm{AOR},(95 \% \mathrm{Cl})$} \\
\hline & Unmet, $\mathrm{n}(\%)(n=224)$ & Met, $\mathrm{n}(\%)(n=213)$ & & \\
\hline \multicolumn{5}{|l|}{$\overline{\text { Age }}$} \\
\hline $36-45$ & $167(78.77 \%)$ & 45 (21.23\%) & $19.3^{* *}(10.14-36.7)$ & $4.12^{*}(1.46-11.76)$ \\
\hline $46-55$ & $42(31.82 \%)$ & $90(68.18 \%)$ & $2.43^{*}(1.25-4.7)$ & $0.96(0.40-2.32)$ \\
\hline$>56$ & $15(16.130 \%)$ & 78 (83.87\%) & 1.00 & 1.00 \\
\hline \multicolumn{5}{|l|}{ Sex } \\
\hline Female & $130(58.3 \%)$ & $93(41.7 \%)$ & $1.78^{*}(1.22-2.61)$ & $2.50^{* *}(1.51-4.15)$ \\
\hline Male & $94(43.9 \%)$ & $120(56.1 \%)$ & 1.00 & 1.00 \\
\hline \multicolumn{5}{|l|}{ Educational status } \\
\hline Diploma & $88(79.28 \%)$ & $23(20.72 \%)$ & $7.3^{* *}(3.1-17.29)$ & $0.59(0.18-1.95)$ \\
\hline Degree & $125(42.5 \%)$ & 169 (57.5\%) & $1.41(0.66-3.04)$ & $0.39(0.14-1.06)$ \\
\hline $\mathrm{MSc} / \mathrm{MA}$ & $11(34.38 \%)$ & $21(65.62 \%)$ & 1.00 & 1.00 \\
\hline \multicolumn{5}{|l|}{ Marital status } \\
\hline Single & $26(50 \%)$ & $26(50 \%)$ & $0.94(0.53-1.69)$ & $1.05(0.48-2.30)$ \\
\hline Married & $198(51.43 \%)$ & 187 (49.57\%) & 1.00 & 1.00 \\
\hline \multicolumn{5}{|c|}{ Monthly income in ETB } \\
\hline $2748-5250$ & $157(71.04 \%)$ & 64 (29.96\%) & $10.43^{* *}(5.23-20.84)$ & $0.86(0.30-2.50)$ \\
\hline $5251-7800$ & 55 (35.9\%) & $98(64.1 \%)$ & $2.39^{*}(1.17-4.85)$ & $1.96(0.93-3.92)$ \\
\hline$>7800$ & $12(19.04 \%)$ & $51(80.96 \%)$ & 1.00 & 1.00 \\
\hline \multicolumn{5}{|l|}{ Type of school } \\
\hline Private & $122(65.95 \%)$ & $63(34.05 \%)$ & $1.99 *(1.34-2.95)$ & $0.68(0.39-1.21)$ \\
\hline Public & $102(40.48 \%)$ & 150 (59.52\%) & 1.00 & 1.00 \\
\hline \multicolumn{5}{|l|}{ Level of school } \\
\hline Primary & $191(54.26 \%)$ & 161 (45.74\%) & $1.87^{*}(1.15-3.03)$ & $1.96(0.93-3.92)$ \\
\hline Secondary & $33(38.8 \%)$ & $52(61.2 \%)$ & 1.00 & 1.00 \\
\hline \multicolumn{5}{|l|}{ Teaching stream } \\
\hline Social science & $109(54.2 \%)$ & $92(45.8 \%)$ & $1.24(0.86-1.82)$ & $0.92(0.55-1.54)$ \\
\hline Natural science & $115(48.7 \%)$ & $121(51.3 \%)$ & 1.00 & 1.00 \\
\hline \multicolumn{5}{|c|}{ Awareness of presbyopia } \\
\hline Unaware & $152(63.6 \%)$ & 87 (36.4\%) & $3.06 * 8(2.07-4.52 \%)$ & $2.36^{*}(1.2-4.66)$ \\
\hline Aware & $72(36.4 \%)$ & $126(63.6)$ & 1.00 & 1.00 \\
\hline \multicolumn{5}{|c|}{ Awareness of place for refraction } \\
\hline Unaware & $146(63.2 \%)$ & $85(36.8 \%)$ & $2.82^{* *}(1.91-4.16)$ & $0.71(0.36-1.42)$ \\
\hline Aware & 78 (37.9\%) & $128(62.1 \%)$ & 1.00 & 1.00 \\
\hline \multicolumn{5}{|c|}{ History of eye examination } \\
\hline No & $148(71.5 \%)$ & $59(28.5 \%)$ & $5.08^{* *}(3.38-7.65)$ & $1.28(0.71-2.30)$ \\
\hline Yes & $76(33.04 \%)$ & $154(66.96 \%)$ & 1.00 & 1.00 \\
\hline \multicolumn{5}{|c|}{ Family ocular history } \\
\hline No & $152(69.7 \%)$ & $66(30.3 \%)$ & $4.7^{*}(3.14-7.0)$ & $1.23(0.65-2.32)$ \\
\hline Yes & $72(32.9 \%)$ & $147(67.1 \%)$ & 1.00 & 1.00 \\
\hline \multicolumn{5}{|c|}{ Self-rating of their current vision } \\
\hline Good & $41(21.7 \%)$ & $148(78.3 \%)$ & $10.16^{* *}(6.5-15.8)$ & $3.5^{*}(1.61-7.65)$ \\
\hline Poor & $183(73.8 \%)$ & 65 (26.2\%) & 1.00 & 1.00 \\
\hline
\end{tabular}


Table 2 Factors associated with the unmet need for presbyopia correction among school teachers in Hawassa city, South Ethiopia $(n=437)$ (Continued)

\begin{tabular}{|c|c|c|c|c|}
\hline \multirow[t]{2}{*}{ Variables } & \multicolumn{2}{|l|}{ Status of presbyopia } & \multirow[b]{2}{*}{ COR, $(95 \% \mathrm{Cl})$} & \multirow[b]{2}{*}{$\mathrm{AOR},(95 \% \mathrm{Cl})$} \\
\hline & Unmet, $\mathrm{n}(\%)(n=224)$ & Met, $\mathrm{n}(\%)(n=213)$ & & \\
\hline \multicolumn{5}{|c|}{ Degree of presbyopia } \\
\hline N10 & $48(66.7 \%)$ & $24(33.3 \%)$ & $11.88^{* *}(5.84-24)$ & $1.37(0.49-3.84)$ \\
\hline N12-N18 & $159(64.4 \%)$ & $88(35.6 \%)$ & $10.74(6.03-19.1)$ & $2.28(0.98-5.29)$ \\
\hline Worse than N18 & $17(14.4 \%)$ & $101(85.6 \%)$ & 1.00 & 1.00 \\
\hline
\end{tabular}

$* P$-value $<0.05^{* *}=p$-value $<0.001$

the unmet need for presbyopia correction in studies done in Bahir Dar city, North West Ethiopia [17], and China [10]. This might be due to more near visual reduction in those 56 years and older necessitates them to have correction compared to the younger age group 3645 years.

The current study found that the unmet need for presbyopia was nearly 2.36 times more in individuals who were unaware of presbyopia as compared to those aware of it. A previous study in Nigeria [15] and China [10], showed that lack of awareness of presbyopia was a barrier to obtaining presbyopia correction. In Nigeria, Info Township [15], (23.7\%), and Ido local governments of Nigeria [18], (34.7\%) were left uncorrected for presbyopia due to unaware of it. In China [10], 28.8\% of subjects without correction reported a lack of being aware as a barrier. This might be since awareness of eye problems influences eye healthcare-seeking behavior. In the current study, $71 \%$ of study participants who were aware of presbyopia had a history of eye examination, which indicates that eye healthcare-seeking behavior is higher among individuals having awareness of presbyopia.

Individuals, who rate their current vision as good were 3.5 times more likely to have an unmet need for presbyopia correction compared to their counterpart rating as poor. In a previous study, in Indonesia [12], perception of their current vision as normal by the participants was reported as one of the barriers for seeking presbyopia correction. Most of the study participants were from primary schools where most of the teaching materials were written with large font size and picture compounded with increased computer use, mostly used at distance beyond $40 \mathrm{~cm}$ which minimizes near vision difficulty until a late stage of presbyopia which makes them left undetected and uncorrected.

\section{Conclusions}

The unmet need for presbyopia correction among school teachers in the study area was ranked as a moderate priority area for intervention by WHO criteria for prioritization of presbyopia services. Being female, aged 36-45 years, lack of awareness about presbyopia and misperception of their current near visual status were factors affecting presbyopia correction. Since the factors affecting the unmet need for presbyopia correction identified in this study can be influenced by health education and vision screening, the Ethiopian federal ministry of health should facilitate eye health information dissemination concerning presbyopia through mass media. Also, the South Nations Nationalities Peoples State Health Bureau has to create linkage with different nongovernmental organizations which work on eye-related activities to establish a school-based eye health program involving visual acuity screening, refraction, and spectacle provision. Similarly, eye health care professionals should provide health education on presbyopia and near visual impairment with a school-based refractive error correction campaign.

\section{Abbreviations}

VA: Visual Acuity; N: Symbol represent point notation of near visual acuity chart; E- chart: Illiterate Tumbling Chart; EBT: Ethiopian Total Birr; MSc: Master of Science; MA: Master of Art

\section{Acknowledgments}

The authors thank the University of Gondar for financial support to conduct this study.

\section{Authors' contributions}

In the process of conducting this project, BN provided the conception, acquisition, design, organization of data, analysis, and interpretation of data; MB had supervised data collection, developed the manuscript and ensured that all the authors approved the manuscript before submission; NF revised data analysis and interpretation, and gave professional consultation and comment. Final all authors made substantial contributions by took part in revising the article critically for important intellectual content; gave final approval of the version to be published; and agree to be accountable for all aspects of the work.

\section{Funding}

The University of Gondar has provided financial support to conduct fieldwork of this research project. But it had no role in the design of the study and collection, analysis, and interpretation of data and in writing the manuscript.

\section{Availability of data and materials}

The dataset on which the conclusion was made is available on request from Minychil Bantihun Munaw/minychilmedban@gmail.com or Balcha Negese/ balchanege@gmail.com

\section{Ethics approval and consent to participate}

Before conducting the study, ethical clearance was obtained from School of Medicine, Ethical review committee, University of Gondar. An official letter was obtained from Gondar University College of Medicine and the Health Sciences Department of Optometry and Hawassa City Health Bureau. Besides, a permission letter was obtained from each school director after a brief explanation of the purpose of the study for school directors. Written informed consent was obtained from each study participant after explaining the aim of the study to proceed to the 
examination and interview step. The confidentiality of the data was ensured and the consent declared that participants' participation is voluntary. They were also informed that there is no any risk through participating in this survey. It was also clarified that they have full right to refuse from participating in the study and to withdraw at any time they wish. They would also have a full right to contact and ask the authors whatever they want.

\section{Consent for publication}

This is not applicable because it doesn't consist of an individual's data.

\section{Competing interests}

We, the authors, report that there is no conflict of interest in this work.

\section{Author details}

${ }^{1}$ Department of Optometry, College of Medicine and Health Sciences, University of Gondar, P.O.Box: 196, Gondar, Ethiopia. ${ }^{2}$ Department of Ophthalmology and Optometry, College of Medicine and Health Sciences, University of Hawassa, Hawassa, Ethiopia.

Received: 4 January 2020 Accepted: 27 April 2020

Published online: 07 May 2020

\section{References}

1. Sherwin JC, Keeffe JE, Kuper H, Islam FA, Muller A, Mathenge W. Functional presbyopia in a rural Kenyan population: the unmet presbyopic need. Clin Exp Ophthalmol. 2008;36(3):245-51.

2. Fricke TR, Tahhan N, Resnikoff S, Papas E, Burnett A, Ho SM, et al. Global prevalence of presbyopia and vision impairment from uncorrected presbyopia: a systematic review, meta-analysis, and modeling. Ophthalmology. 2018;125(10):1492-9.

3. Ntodie M, Abu SL, Kyei S, Abokyi S, Abu EK. Near vision spectacle coverage and barriers to near vision correction among adults in the Cape Coast Metropolis of Ghana. Afr Health Sci. 2017;17(2):549-55.

4. Kumah D, Lartey S, Amoah-Duah K. Presbyopia among public senior high school teachers in the Kumasi metropolis. Ghana Med J. 2011;45(1):27-30.

5. Resnikoff S, Pascolini D, Mariotti SP, Pokharel GP. Global magnitude of visual impairment caused by uncorrected refractive errors in 2004. Bull World Health Organ. 2008;86:63-70.

6. Chinawa NE, Pedro-Egbe CN. Barriers to Uptake of Presbyopic Correction among Primary and Secondary Teachers in Public Schools in B/K-Dere Communities in Rivers State, Nigeria. Adv Ophthalmol Vis Syst. 2016;5(3):00161.

7. Laitinen A, Koskinen S, Härkänen T, Reunanen A, Laatikainen L, Aromaa A. A nationwide population-based survey on visual acuity, near vision, and selfreported visual function in the adult population in Finland. Ophthalmology. 2005;112(12):2227-37.

8. Duarte WR, Barros AJ, Dias-da-Costa JS, Cattan JM. Prevalence of near vision deficiency and related factors: a population-based study in Brazil. Cadernos de Saude Publica. 2003;19(2):551-9.

9. Hookway LA, Frazier M, Rivera N, Ramson P, Carballo L, Naidoo K Population-based study of presbyopia in Nicaragua. Clin Exp Optom. 2016; 99(6):559-63.

10. Lu Q, He W, Murthy GVS, He X, Congdon N, Zhang L, et al. Presbyopia and near-vision impairment in rural northern China. Invest Ophthalmol Vis Sci. 2011;52(5):2300

11. Marmamula S, Narsaiah S, Shekhar K, Khanna RC. Presbyopia, spectacles use, and spectacle correction coverage for near vision among cloth weaving communities in Prakasam district in South India. Ophthalmic Physiol Opt. 2013;33(5):597-603.

12. Ehrlich JR, Laoh A, Kourgialis N, Prasetyanti W, Zakiyah R, Faillace S, et al. Uncorrected refractive error and presbyopia among junior high school teachers in Jakarta, Indonesia. Ophthal Epidemiol. 2013;20(6):369-74.

13. Bourne RR, Dineen BP, Huq DMN, Ali SM, Johnson GJ. Correction of refractive error in the adult population of Bangladesh: meeting the unmet need. Invest Ophthalmol Vis Sci. 2004;45(2):410-7.

14. Muhit M, Minto H, Parvin A, Jadoon MZ, Islam J, Yasmin S, et al. Prevalence of refractive error, presbyopia, and unmet need of spectacle coverage in a northern district of Bangladesh: rapid assessment of refractive error study. Ophthalmic Epidemiol. 2018;25(2):126-32.

15. Idowu OO, Aribaba OT, Onakoya AO, Rotimi-Samuel A, Musa KO, Akinsola FB. Presbyopia and near spectacle correction coverage among public school teachers in Ifo township, South-West Nigeria. Niger Postgrad Med J. 2016;23(3):132.

16. Laviers HR, Omar F, Jecha H, Kassim G, Gilbert C. Presbyopic spectacle coverage, willingness to pay for near correction, and the impact of correcting uncorrected presbyopia in adults in Zanzibar, East Africa. Invest Ophthalmol Vis Sci. 2010;51(2):1234-41..

17. Girum M, Desalegn Gudeta A, Shiferaw AD. Determinants of high unmet need for presbyopia correction: a community-based study in north West Ethiopia. Clin Optom. 2017;9:25-31.

18. Seidu M, Bekibele C, Ayorinde A. Presbyopic spectacle coverage and barriers to near vision correction among the adult population in ido local government area, Southwest Nigeria. J Clin Sci. 2017;14(4):188.

19. Usha Raman P. 2,4, Srinivas Marmamula M, 2,5, Jill E Keeffe P, 3, Gullapalli N Rao M. Barriers to Utilisation of Refraction Services in South India. Biomed J Open. 2011;16(5):8-22

20. Uche J, Ezegwui I, Uche E, Onwasigwe E, Umeh R, Onwasigwe C. Prevalence of presbyopia in a rural African community. Rural Remote Health. 2014;14:2731.

21. Chan VF, Mebrahtu G, Ramson P, Naidoo KS. Prevalence of Refractive Error and Spectacle Coverage in Zoba Ma'ekel Eritrea: A Rapid Assessment of Refractive Error. Ophthal Epidemiol. 2013;20(3):131-7.

22. Sapkota Y, Dulal S, Pokharel G, Pant B, Ellwein L. Prevalence and correction of near vision impairment at Kaski, Nepal. Nepalese J Ophthalmol. 2012;4(1):17.

23. Mashayo ER, Chan VF, Ramson P, Chinanayi F, Naidoo KS. Prevalence of refractive error, presbyopia, and spectacle coverage in Kahama District, Tanzania. Clin Exp Optom. 2015;98:58-64 2015; 98( 58).

24. Nsubuga N, Ramson P, Govender P, Chan V, Wepo M, Naidoo KS. Uncorrected refractive errors, presbyopia, and spectacle coverage in Kamuli District, Uganda. Afr Vis Eye Health. 2016;75(1):1-6.

25. Ramke J, Du Toit R, Palagyi A, Brian G, Naduvilath T. Correction of refractive error and presbyopia in Timor-Leste. Br J Ophthalmol. 2007;91(7):860-6.

\section{Publisher's Note}

Springer Nature remains neutral with regard to jurisdictional claims in published maps and institutional affiliations.

Ready to submit your research? Choose BMC and benefit from:

- fast, convenient online submission

- thorough peer review by experienced researchers in your field

- rapid publication on acceptance

- support for research data, including large and complex data types

- gold Open Access which fosters wider collaboration and increased citations

- maximum visibility for your research: over $100 \mathrm{M}$ website views per year

At $\mathrm{BMC}$, research is always in progress.

Learn more biomedcentral.com/submissions 